\title{
Impact of Weight Loss on the Metabolic Syndrome
}

S. Phelan, Brown Medical School/The Miriam Hospital, Providence, RI, USA,

T. A. Wadden, University of Pennsylvania School of Medicine, Philadelphia, PA, USA

R. I. Berkowitz, University of Pennsylvania School of Medicine, Philadelphia, PA, USA

D. B. Sarwer, University of Pennsylvania School of Medicine, Philadelphia, PA, USA

L. G. Womble, University of Pennsylvania School of Medicine, Philadelphia, PA, USA

R. K. Cato, University of Pennsylvania School of Medicine, Philadelphia, PA, USA, and

R. Rothman, University of Pennsylvania School of Medicine, Philadelphia, PA, USA

\begin{abstract}
Objective:

To evaluate the effects of weight loss on the risk of having metabolic syndrome after 1 year of treatment with lifestyle modification alone, pharmacotherapy alone (sibutramine) or the combination of the two.
\end{abstract}

\section{Design:}

Randomized, controlled, 1-year clinical trial.

\section{Patients:}

One hundred and eighty women and 44 men, 18-65 years of age, with a body mass index of $30-45 \mathrm{~kg} / \mathrm{m}^{2}$, free of uncontrolled hypertension or type 1 or 2 diabetes.

\section{Intervention:}

Fifteen milligrams of sibutramine per day alone, lifestyle modification counseling alone, sibutramine plus lifestyle modification counseling or sibutramine plus brief lifestyle modification counseling.

\section{Measurements:}

The metabolic syndrome, as defined by the Adult Treatment Panel III.

\section{Results:}

Before treatment, $34.8 \%$ of the participants had the metabolic syndrome. Metabolic syndrome was more prevalent in Caucasians than African Americans (42.5 vs 20.3\%; $\mathrm{P}<0.03$ ), in males than females (65.1 vs $34.9 \% ; \mathrm{P}<0.002$ ) and in older ( $>44$ years) than younger ( $\leq 44$ years) participants $(47.5 \mathrm{vs} 20.8 \%$;

$\mathrm{P}<0.0001)$. After 1 year of treatment, a moderate decrease in weight $(8.0 \pm 8.7 \mathrm{~kg})$ resulted in significant reductions in the prevalence of metabolic syndrome from 34.8 to $27.2 \%$ of all participants $(\mathrm{P}<0.02)$.

Logistic regression analyses indicated that for each $1 \mathrm{~kg}$ of weight lost, the odds of metabolic syndrome were reduced by $8 \%(\mathrm{CI}=0.89-0.97 ; \mathrm{P}<0.003)$. Lifestyle modification either alone $(\mathrm{P}<0.04)$, or in 
combination with sibutramine $(\mathrm{P}<0.05)$, significantly reduced the prevalence of metabolic syndrome compared with sibutramine alone. The group effect was removed after controlling for weight loss.

\section{Conclusions:}

The metabolic syndrome was prevalent in over one-third of obese individuals who sought weight loss treatment, and the prevalence differed by age, sex and ethnicity. Moderate weight loss markedly reduced the odds of metabolic syndrome in this sample.

\section{Keywords:}

metabolic syndrome, sibutramine, behavioral treatment, weight loss, Adult Treatment Panel III 


\section{Introduction}

The metabolic syndrome is a major public health problem in the United States, affecting almost onefourth of the adult population. ${ }^{1}$ People who have this syndrome are at increased risk for developing type 2 diabetes and cardiovascular disease..$^{2,3,4}$ Thus, finding ways to ameliorate metabolic syndrome and its comorbidities is critical.

Weight loss is associated with improvement in cardiovascular disease risk factors and reduced risk of type 2 diabetes and, along with physical activity, is recommended as the first line of treatment for metabolic syndrome. ${ }^{6}$ Short-term studies have shown that weight loss improves metabolic syndrome ${ }^{7,8,9,10}$ and its individual components. ${ }^{11,12}$ However, few long-term studies have been conducted. Orchard et al. ${ }^{13}$ found that a lifestyle intervention that produced a $7 \%$ weight loss reduced the prevalence of metabolic syndrome by $15.6 \%$ in participants followed for a mean of 3.2 years. However, the sample was restricted to individuals with impaired glucose tolerance and a body mass index (BMI) $\geq 24 \mathrm{~kg} / \mathrm{m}^{2}$. Després et al. ${ }^{14}$ found that a 7\% weight loss achieved with lifestyle modification and rimonabant reduced the prevalence of metabolic syndrome by $52 \%$ after 1 year of treatment. However, the authors speculated that improvements in the syndrome were partially attributable to the effects of rimonabant alone, independent of those of weight loss. Other authors also have reported an effect of rimonabant on components of the metabolic syndrome independent of weight loss. ${ }^{15,16}$

The present study examined the effect of weight loss on 1-year prevalence of metabolic syndrome in obese patients who received lifestyle modification alone, pharmacotherapy alone (sibutramine) or the combination of the two. We predicted that greater weight loss, achieved by lifestyle modification alone, or in combination with pharmacotherapy, would be associated with greater reduction in the prevalence of metabolic syndrome.

\section{Methods}

\section{Participants}

Participants were 180 women and 44 men $(N=224)$ who participated in a 1-year randomized controlled trial of lifestyle modification and pharmacotherapy for obesity. The study's protocol and principal outcomes have been reported previously. ${ }^{17}$ As shown in Table 1, the majority of participants were Caucasian (65.2\%); 30.9\% were African-American. Participants had an average age of $43.6 \pm 10.2$ years, weight of $107.0 \pm 17.2 \mathrm{~kg}$ and BMI of $37.8 \pm 4.2 \mathrm{~kg} / \mathrm{m}^{2}$. Main inclusion criteria were an age of $18-65$ years and BMI of $30-45 \mathrm{~kg} / \mathrm{m}^{2}$. Principal exclusion criteria were types 1 or 2 diabetes (as judged by the participants' primary care physicians); uncontrolled hypertension ( $>140 / 90 \mathrm{~mm} \mathrm{Hg})$; cerebrovascular, cardiovascular, kidney, or liver disease; pregnancy or lactation; the use of medications known to affect body weight; and major psychiatric disorders.

\section{Treatment}

The 224 participants were randomly assigned to one of four treatment conditions: (1) sibutramine alone; (2) group lifestyle modification alone; (3) sibutramine plus group lifestyle modification (i.e., combined therapy); or (4) sibutramine plus brief practitioner-delivered lifestyle modification (i.e., drug plus brief therapy). As described previously, ${ }^{17}$ the first treatment consisted of sibutramine alone (15 mg/day), which was monitored by a primary care provider at weeks $1,3,6,10,18,26,40$ and 52 . Lifestyle modification alone consisted of weekly group meetings from weeks $1-18$, biweekly sessions from weeks $20-40$, and a follow-up visit at week 52. Combined therapy provided the combination of sibutramine and group lifestyle modification. Sibutramine plus brief therapy consisted of 10-15 min visits with a primary care provider at weeks $1,3,6,10,18,26,40$, and 52. During these visits, medication was monitored, and 
participants also received two treatment manuals ${ }^{18,19}$ and instruction in completing food and activity records (as did participants in the two group lifestyle modification conditions).

Thirty-nine participants (17.4\%) did not complete the 1-year study. This number includes any individual who attended the first treatment visit and did not return. There were no significant differences in attrition among the four treatment groups, as described previously. ${ }^{17}$ Written informed consent was obtained from all participants, and this study was approved by the University of Pennsylvania's institutional review board. This research was supported by grants DK56124 and DK065018 from the National Institutes of Diabetes, Digestive and Kidney Disease. Abbott Laboratories provided the medication used in the study.

\section{Measures}

Weight

Weight was measured at all treatment visits and at baseline and weeks 18, 40 and 52 on a digital scale (Detecto, model 6800), with participants dressed in light clothing without shoes.

\section{Serum chemistries}

Blood samples were drawn at baseline and weeks 18, 40 and 52 following an overnight fast.

Triglycerides, total cholesterol, low-density lipoprotein cholesterol, high-density lipoprotein (HDL) cholesterol, insulin and glucose were measured (Quest Diagnostics, Horsham, PA, USA). Insulin sensitivity was estimated by the homeostasis model of insulin sensitivity (HOMA). ${ }^{20}$

\section{Blood pressure and pulse}

Blood pressure and pulse were measured by research assistants using a Dinamap monitor (Johnson \& Johnson, XL model 9300). Two readings were taken at 1-min intervals after participants had been seated for $\geq 5$ min. Measurements were obtained at all treatment visits, as well as at baseline and weeks 18, 40 and 52 .

Definition of the metabolic syndrome Metabolic syndrome was defined according to criteria from the National Cholesterol Education Program's Adult Treatment Panel III, ${ }^{6}$ which requires that three or more of the following conditions be met: (1) waist circumference greater than $102 \mathrm{~cm}$ in men and $88 \mathrm{~cm}$ in women; (2) serum triglyceride level of at least $1.7 \mathrm{mmol} / \mathrm{l}(\geq 150 \mathrm{mg} / \mathrm{dl})$; (3) HDL cholesterol level less than $1.03 \mathrm{mmol} / \mathrm{l}(<40 \mathrm{mg} / \mathrm{dl})$ in $\mathrm{men}$ and less than $1.3 \mathrm{mmol} / 1(<50 \mathrm{mg} / \mathrm{dl})$ in women; (4) blood pressure of at least $130 \mathrm{~mm} \mathrm{Hg}$ systolic or $85 \mathrm{~mm}$ $\mathrm{Hg}$ diastolic; and (5) fasting plasma glucose level of $6.2 \mathrm{mmol} / \mathrm{l}(110 \mathrm{mg} / \mathrm{dl})$. Participants who were being treated with blood pressure or triglyceride-lowering medications were classified as positive for the respective criterion. We chose the ATP III criteria for their clinical utility and to be consistent with other studies. ${ }^{13,14}$

\section{Statistics}

Logistic regression analyses were used to examine differences in prevalence of metabolic syndrome at baseline and week 52. At baseline, analyses examined the prevalence of metabolic syndrome across different age, ethnicity and gender categories. At week 52, analyses examined the prevalence of metabolic syndrome after adjusting for baseline prevalence of the syndrome, group, age, ethnicity and gender. Logistic regression analyses also were used to examine group differences in prevalence of metabolic syndrome, adjusting for ethnicity, age and gender. Weight was later entered as an additional covariate in the analyses.

There were no significant differences between groups in baseline demographic variables or in the prevalence of metabolic syndrome. $\chi^{2}$ analyses were used to examine group differences after 1 year of treatment in proportions of cases that developed the metabolic syndrome (i.e., did not meet criteria at baseline but did at the 1-year assessment) or resolved it (i.e., met criteria at baseline but not at the 1-year assessment). Similar analyses were used to examine 1-year group differences in the development and 
resolution of the components of the metabolic syndrome. Weight data were examined for all persons who began treatment using an intention-to-treat analysis in which participants who discontinued treatment were assumed to regain $0.3 \mathrm{~kg} /$ months after leaving the study. ${ }^{17}$ Data for the metabolic syndrome components were examined using a last-observation-carried forward (LOCF) analysis.

\section{Results}

\section{Baseline prevalence of the metabolic syndrome}

Figure 1 shows that, before treatment, $34.8 \%$ of the participants met the criteria for the metabolic syndrome. The prevalence of the syndrome was significantly greater in Caucasians than African Americans ( 42.5 vs $20.3 \% ; P<0.03$ ), in males than females $(65.1$ vs $34.9 \% ; P<0.002)$ and in older $(>44$ years) than younger ( $\leq 44$ years) participants $(47.5$ vs $20.8 \% ; P<0.0001)$. The severity of metabolic syndrome, in terms of the number of the five criteria met at baseline $(M=2.2 \pm 1.0)$, did not differ significantly by age, ethnicity, or gender. Figure 1 also shows that, before treatment, $100 \%$ of participants had an elevated waist circumference, and $45.5 \%$ had high blood pressure. High HDL cholesterol, triglycerides and blood glucose followed in this order.

\section{Metabolic syndrome after weight loss}

Study participants $(N=224)$ lost an average of $8.0 \pm 8.7 \mathrm{~kg}(7.5 \pm 7.9 \%$ of initial body weight $)$ after 1 year of treatment. This weight loss was associated with a significant $(P<0.02)$ reduction in the prevalence of metabolic syndrome, from 34.8 to $27.2 \%$ of participants. Logistic regression analyses indicated that for each $1 \mathrm{~kg}$ of weight lost, the odds of having metabolic syndrome at the 1-year assessment were reduced by $8 \%(\mathrm{CI}=0.89-0.97 ; P<0.003)$, after adjusting for demographic variables, baseline metabolic syndrome status and treatment group. The relationship between weight loss and 1-year prevalence of metabolic syndrome appeared linear (point-biserial correlation $=0.20, P<0.003$ ).

Participants who lost $\geq 5 \%$ of initial body weight had a $59.2 \%$ reduction in the odds of having metabolic syndrome compared with those losing $<5 \%(\mathrm{CI}=0.20-0.85 ; P<0.02)$. Participants who lost $\geq 10 \%$ of initial body weight had an $83.2 \%$ reduction in odds of having metabolic syndrome compared with those who lost $<10 \%$ (CI=0.07-0.42; $P<0.0001)$.

Table 2 illustrates resolution and incidence rates of the metabolic syndrome and its components after 1 year of treatment. Of the 78 participants who met the criteria for the syndrome at baseline, $46.2 \%$ no longer met them at the 1 -year assessment. Only $13.0 \%$ of the 146 participants who did not meet criteria for metabolic syndrome at baseline developed the syndrome after the year of treatment.

\section{Changes in metabolic syndrome across treatment groups}

As reported previously, ${ }^{17}$ the combination of group lifestyle modification and sibutramine induced a loss of $11.0 \pm 8.8 \%$ of initial weight at 1 year, which was significantly greater than that produced by sibutramine alone $(4.7 \pm 6.7 \%)$, lifestyle modification alone $(6.7 \pm 7.8 \%)$ and drug plus brief therapy $(7.0$ $\pm 7.7 \%$ ). The latter three groups did not differ significantly from each other in weight loss at the 1 -year assessment.

Logistic regression analyses indicated that, compared with the sibutramine alone condition, lifestyle modification alone and combined therapy reduced the odds of having metabolic syndrome by $66.3 \%$ $(P<0.04 ; \mathrm{CI}=0.12-0.93)$ and $60.1 \%(P<0.05 ; \mathrm{CI}=0.15-0.99)$, respectively, after adjusting for baseline metabolic syndrome status and demographic variables. No significant effect was found for the drug plus brief therapy group. When weight loss was entered as a covariate, all group differences in the 1-year odds of having metabolic syndrome were removed, suggesting that there was no effect of the separate treatments, independent of the weight loss associated with them. 
Table 3 shows that rates of resolving and developing metabolic syndrome across the four treatment groups at the 1-year assessment. The greatest number of cases of metabolic syndrome was resolved in the lifestyle modification alone (72.2\%) and combined therapy (61.9\%) groups, which did not differ significantly from each other. There were no significant differences in the development (i.e., incidence) of metabolic syndrome in the three groups that received sibutramine vs lifestyle modification alone (average of 10 vs $4 \%$ ).

Table 4 shows the 1-year prevalence rate of the metabolic syndrome, as well as rates of resolving or developing the components of the metabolic syndrome in the four treatment groups. There were no statistically significant differences across the groups in the resolution or development of hyperglycemia, low HDL cholesterol, or high waist circumference. As reported previously, ${ }^{17}$ there were also no statistically significant differences across the groups in 1-year changes in HOMA (which changed from $4.8 \pm 5.8$ to $4.4 \pm 5.9$ in the sibutramine alone group, $3.9 \pm 2.7$ to $2.8 \pm 2.1$ in the lifestyle modification alone, $3.9 \pm 2.2$ to $2.8 \pm 2.0$ in combined therapy and $5.0 \pm 4.5$ to $3.9 \pm 4.5$ in the drug plus brief therapy group). However, the combined therapy and lifestyle modification alone groups appeared to reduce the prevalence of high blood pressure and high triglycerides to a greater extent than the sibutramine alone and drug plus brief therapy and groups.

Given concerns that norepinephrine reuptake inhibition with sibutramine could exacerbate arterial hypertension, we compared the combined therapy and lifestyle modification alone groups on the rates of resolving and developing high blood pressure (i.e., $\geq 130 / 85 \mathrm{~mm} \mathrm{Hg}$ ). No significant differences were observed; $8.3 \%$ of persons in the combined therapy group and $7.7 \%$ of cases in the lifestyle modification groups developed high blood pressure over the 1-year study. Among participants who had high blood pressure at baseline, $50.0 \%$ of cases in the combined therapy group and $34.5 \%$ of cases in lifestyle modification alone group were resolved at the 1-year follow-up (Table 4). The combined therapy and lifestyle modification alone groups also did not significantly differ on any of the other metabolic syndrome components (Table 4$)$. Analyses stratified by weight loss category $(<5,5-10$ and $>10 \%$ weight losses) revealed similar findings.

\section{Discussion}

The metabolic syndrome was prevalent in over one-third of obese individuals who sought weight loss treatment in this study, a value which is higher than the national average of $22 \%$ of American adults. ${ }^{1}$ Given that the main components of metabolic syndrome are all associated with excess weight (i.e., waist circumference, blood pressure, glucose and lipid levels), the greater prevalence of the metabolic syndrome in our sample is not surprising. Moreover, it would have been even higher if we had not excluded persons with type 2 diabetes from this trial. (We note that participants' primary care physicians reported that participants were free of diabetes, but approximately $10 \%$ of our sample had a baseline fasting blood sugar level $\geq 126 \mathrm{mg} / \mathrm{dl}$.) The prevalence of metabolic syndrome was greater among older participants, Caucasians and males in our sample. Similar findings have been reported elsewhere for age. ${ }^{1}$ Findings on ethnicity ${ }^{21,22}$ and gender ${ }^{1}$ have been equivocal.

Lifestyle modification, either alone or in combination with sibutramine, reduced the prevalence of metabolic syndrome significantly. (The prevalence was affected by cases in which the syndrome either developed or resolved.) After 1 year of treatment, the prevalence of the metabolic syndrome declined by $44 \%$ in the lifestyle modification alone group and $48 \%$ in the combined therapy group compared with a $5 \%$ reduction in the sibutramine alone condition. Other studies have reported similar reductions in prevalence of metabolic syndrome after combined medication and lifestyle modification treatments. Despres et al. ${ }^{14}$ reported a $52 \%$ reduction in the prevalence of metabolic syndrome after 1 year of treatment with lifestyle modification and rimonabant $20 \mathrm{mg}$ /day. Pi-Sunyer et al. ${ }^{15}$ reported a $40 \%$ reduction in the prevalence of metabolic syndrome after 1 year of treatment with rimonabant $20 \mathrm{mg} /$ day and dietary counseling. 
Lifestyle modification, alone or in combination with sibutramine, had a dramatic effect on the resolution of metabolic syndrome. Among participants who had the syndrome at baseline, $72 \%$ of the lifestyle modification alone and $62 \%$ of combined therapy groups no longer had the syndrome after 1 year of treatment (compared with $37 \%$ of the sibutramine alone group). Resolution rates were not reported in the 1-and 2-year studies of rimonobant. ${ }^{14,15}$ However, the resolution rates in our study were higher than those observed after 3.2 years of lifestyle modification in participants with impaired glucose tolerance in the Diabetes Prevention Program (DPP), at which time 38\% of participants who received the lifestyle intervention no longer had the syndrome. ${ }^{13}$

Weight loss appeared to be the driving force behind the reductions in metabolic syndrome in our sample. After adjusting for weight loss, group differences in the 1-year prevalence of metabolic syndrome disappeared. In the sample as a whole, a loss of $5 \%$ or more of initial body weight reduced the odds of having metabolic syndrome by $59 \%$. Similar findings have been reported elsewhere. In a sample of obese middle-aged men with a high prevalence $(60 \%)$ of metabolic syndrome, Kukkonen-Harjula et al. ${ }^{23}$ found that a $4.8 \mathrm{~kg}$ weight loss reduced the odds of having metabolic syndrome by $71 \%$ at the end of a 2.5 -year study. The authors reported similar findings in a study of women. ${ }^{24}$

The lifestyle modification alone and combined therapy groups had comparable effects in reducing the prevalence of metabolic syndrome, despite the former group's losing less weight $(6.7 \pm 7.8 \mathrm{vs} 11.0 \pm$ $8.8 \%$, respectively). The reasons for this are unclear. Prior research has shown that sibutramine, despite inducing significantly more weight loss, did not improve glucose control significantly more than placebo. ${ }^{25}$ Similarly, in the current study the combined therapy and lifestyle modification alone groups did not differ significantly on changes in glucose or insulin sensitivity, as assessed by HOMA. The lack of significant differences between groups in the present study may reflect a lack of statistical power. In addition, we selected patients who were free of type 2 diabetes, thus, limiting the baseline glucose values (and the likelihood of observing clinically significant changes on this measure). Further study is needed of the potential independent effects of sibutramine on glycemic control.

We note that in the current study the addition of sibutramine to lifestyle modification was associated with generally favorable effects on blood pressure. Abnormal blood pressure (i.e., 130/85 $\mathrm{mm} \mathrm{Hg}$ ) resolved in $50.0 \%$ of participants in this condition, compared with $34.5 \%$ of participants in the lifestyle modification alone group. (The difference between groups was not statistically significant.) Thus, even though sibutramine may be associated with small mean increases in pulse and blood pressure, ${ }^{26,27}$ small improvements in blood pressure may be observed in patients treated by 10 to $15 \mathrm{mg} /$ day of sibutramine who lose approximately $10 \%$ of initial weight. However, as was the case with glycemic control, our main study was not designed (or powered) to compare differences in blood pressure between treatment groups. It is possible that participants in the lifestyle modification alone group adopted more favorable dietary (e.g., a lower carbohydrate intake) or physical activity habits, ${ }^{28}$ although we do not have adequate data to test those hypotheses.

This study had several additional limitations. The sample sizes of our groups were small, which may have limited our power to detect significant group differences in the development or resolution of metabolic syndrome and its components. The population was limited to obese individuals who sought weight loss treatment at a university-based clinic, so the findings may not generalize to other populations. We used a LOCF analysis to examine changes in components of the metabolic syndrome, which may have inflated rates of resolution of metabolic syndrome.

In conclusion, we found the metabolic syndrome was prevalent in over one third of obese individuals who sought weight loss treatment, and the prevalence differed by age, sex and ethnicity. Moderate weight loss markedly reduced the odds of having metabolic syndrome, underscoring the value of weight loss in the treatment of this condition. 
Table 1: Baseline Characteristics of Participants

\begin{tabular}{|c|c|c|c|c|}
\hline Characteristic & $\begin{array}{c}\text { Total sample } \\
(\mathrm{N}=\mathbf{2 2 4})\end{array}$ & $\begin{array}{c}\text { Metabolic syndrome } \\
\text { present }(\mathrm{N}=78)\end{array}$ & $\begin{array}{c}\text { No metabolic } \\
\text { syndrome }(\mathrm{N}=146)\end{array}$ & P-value* \\
\hline \multicolumn{5}{|l|}{ Sex (\% subjects) } \\
\hline Female & 80.4 & 62.8 & 89.7 & 0.0001 \\
\hline Male & 19.6 & 37.2 & 10.3 & \\
\hline \multicolumn{5}{|l|}{ Ethnicity (\% subjects) } \\
\hline White & 65.2 & 79.5 & 57.9 & \\
\hline African-American & 30.9 & 17.9 & 37.9 & 0.005 \\
\hline Hispanic & 3.6 & 2.6 & 4.1 & \\
\hline Age (year) & $43.6 \pm 10.2$ & $47.8 \pm 9.9$ & $41.4 \pm 9.7$ & 0.0001 \\
\hline Weight (kg) & $107.0 \pm 17.2$ & $111.2 \pm 18.3$ & $104.7 \pm 16.2$ & 0.007 \\
\hline Height $(\mathrm{cm})$ & $167.9 \pm 8.4$ & $169.6 \pm 9.4$ & $167.0 \pm 7.6$ & 0.04 \\
\hline $\mathrm{BMI}(\mathrm{kg} / \mathrm{m} 2)$ & $37.8 \pm 4.2$ & $38.4 \pm 4.0$ & $37.4 \pm 4.3$ & 0.07 \\
\hline Systolic BP (mm Hg) & $124.7 \pm 14.7$ & $133.4 \pm 13.5$ & $120.0 \pm 13.1$ & 0.0001 \\
\hline Diastolic BP $(\mathrm{mm} \mathrm{Hg})$ & $68.0 \pm 9.8$ & $72.5 \pm 10.2$ & $65.6 \pm 8.7$ & 0.0001 \\
\hline Pulse (bpm) & $78.6 \pm 10.6$ & $80.6 \pm 10.8$ & $77.6 \pm 10.4$ & 0.05 \\
\hline Triglycerides (mg/dl) & $131.1 \pm 102.1$ & $191.1 \pm 137.8$ & $97.3 \pm 51.5$ & 0.0001 \\
\hline \multicolumn{5}{|l|}{ Cholesterol } \\
\hline Total (mg/dl) & $198.2 \pm 33.9$ & $200.5 \pm 33.8$ & $196.6 \pm 33.9$ & 0.42 \\
\hline LDL-C (mg/dl) & $117.7 \pm 29.6$ & $117.9 \pm 29.7$ & $117.3 \pm 29.6$ & 0.87 \\
\hline $\mathrm{HDL}-\mathrm{C}(\mathrm{mg} / \mathrm{dl})$ & $55.2 \pm 14.3$ & $46.4 \pm 10.7$ & $60.0 \pm 13.7$ & 0.0001 \\
\hline Glucose (mg/dl) & $95.2 \pm 13.9$ & $100.8 \pm 13.7$ & $91.8 \pm 10.3$ & 0.0001 \\
\hline Insulin (muU/ml) & $17.9 \pm 13.4$ & $22.6 \pm 17.9$ & $15.3 \pm 9.4$ & 0.001 \\
\hline HOMA & $4.7 \pm 4.4$ & $6.3 \pm 6.2$ & $3.8 \pm 2.6$ & 0.001 \\
\hline
\end{tabular}

Abbreviations: BMI, body mass index; HDL-C, high-density lipoprotein-cholesterol, HOMA, homeostasis model of insulin sensitivity, LDL-C, low-density lipoprotein-cholesterol.

${ }^{*} P$-values represent differences between participants with the metabolic syndrome vs those without the syndrome based on independent $t$-tests (for continuous variables) and $\chi^{2}$ test (for categorical variables).

Note: Values presented are mean \pm s.d.; b.p.m., beats per minute. 
Table 2: Percentage of participants $(N=224)$ who, after 1 year of treatment, resolved or developed the metabolic syndrome, as well as components of the metabolic syndrome

\begin{tabular}{|l|c|c|c|c|}
\hline Criterion & $\begin{array}{c}\text { Baseline } \\
\text { prevalence (\%) }\end{array}$ & $\begin{array}{c}\text { 1-year } \\
\text { prevalence (\%) }\end{array}$ & $\begin{array}{c}\text { \% cases } \\
\text { resolved }\end{array}$ & $\begin{array}{c}\text { \% cases } \\
\text { developed }\end{array}$ \\
\hline Metabolic syndrome & $34.8(\mathrm{~N}=78)$ & $27.2(\mathrm{~N}=61)$ & $46.2(\mathrm{~N}=36)$ & $13.0(\mathrm{~N}=19)$ \\
\hline Waist circumference & $100(\mathrm{~N}=224)$ & $91.5(\mathrm{~N}=205)$ & $8.5(\mathrm{~N}=19)$ & $0(\mathrm{~N}=0)$ \\
\hline Blood pressure & $45.5(\mathrm{~N}=102)$ & $39.3(\mathrm{~N}=88)$ & $31.4(\mathrm{~N}=32)$ & $14.8(\mathrm{~N}=18)$ \\
\hline HDL cholesterol & $33.9(\mathrm{~N}=76)$ & $33.5(\mathrm{~N}=75)$ & $25.0(\mathrm{~N}=19)$ & $12.2(\mathrm{~N}=18)$ \\
\hline Triglycerides & $26.3(\mathrm{~N}=59)$ & $19.6(\mathrm{~N}=44)$ & $49.2(\mathrm{~N}=29)$ & $8.5(\mathrm{~N}=14)$ \\
\hline Glucose & $11.2(\mathrm{~N}=25)$ & $6.3(\mathrm{~N}=14)$ & $68.0(\mathrm{~N}=17)$ & $3.0(\mathrm{~N}=6)$ \\
\hline
\end{tabular}

Abbreviation: HDL, high-density lipoprotein. 
Table 3: Percentage of participants in each group who resolved or developed metabolic syndrome (MS) after 1 year of treatment

\begin{tabular}{|l|c|c|c|c|}
\hline Variable & $\begin{array}{c}\text { Sibutramine alone } \\
\mathbf{( N = 5 5 )}\end{array}$ & $\begin{array}{c}\text { Sibutramine plus brief } \\
\text { therapy }(\mathrm{N}=54)\end{array}$ & $\begin{array}{c}\text { Lifestyle modification } \\
\text { alone }(\mathbf{N}=55)\end{array}$ & $\begin{array}{c}\text { Combined } \\
\text { therapy } \\
(\mathbf{N}=\mathbf{6 0})\end{array}$ \\
\hline Baseline prevalence MS $(\%)$ & $34.5_{\mathrm{a}}(\mathrm{N}=19)$ & $37.0_{\mathrm{a}}(\mathrm{N}=20)$ & $30.0_{\mathrm{a}}(\mathrm{N}=18)$ & $38.2_{\mathrm{a}}(\mathrm{N}=21)$ \\
\hline 1-year prevalence MS $(\%)$ & $32.7_{\mathrm{a}}(\mathrm{N}=18)$ & $40.7_{\mathrm{a}}(\mathrm{N}=22)$ & $18.2_{\mathrm{b}}(\mathrm{N}=10)$ & $18.3_{\mathrm{b}}(\mathrm{N}=11)$ \\
\hline$\%$ cases resolved MS & $36.8_{\mathrm{a}}(\mathrm{N}=7)$ & $15.0_{\mathrm{a}}(\mathrm{N}=3)$ & $72.2_{\mathrm{b}}(\mathrm{N}=13)$ & $61.9_{\mathrm{b}}(\mathrm{N}=13)$ \\
\hline$\%$ cases developed MS & $16.7_{\mathrm{a}}(\mathrm{N}=6)$ & $14.7_{\mathrm{a}}(\mathrm{N}=5)$ & $5.4_{\mathrm{a}}(\mathrm{N}=2)$ & $15.4_{\mathrm{a}}(\mathrm{N}=6)$ \\
\hline
\end{tabular}

Across rows, values with different subscripts differ significantly based on $\chi^{2}$ tests, $P<0.05$. Participants in the sibutramine alone, sibutramine plus brief therapy, lifestyle modification alone, and combined therapy groups lost 4.7 $\pm 6.7,7.0 \pm 7.0,6.7 \pm 7.8$, and $11.0 \pm 8.8 \%$ of initial body weight, respectively. ${ }^{17}$ 
Table 4: Percentage of participants in each group who resolved or developed components of the metabolic syndrome after 1 year of treatment

\begin{tabular}{|c|c|c|c|c|}
\hline Variable & $\begin{array}{l}\text { Sibutramine } \\
\text { alone } \\
(N=55)\end{array}$ & $\begin{array}{l}\text { Sibutramine plus } \\
\text { brief therapy } \\
(N=54)\end{array}$ & $\begin{array}{l}\text { Lifestyle } \\
\text { modification } \\
\text { alone }(N=55)\end{array}$ & $\begin{array}{l}\text { Combined } \\
\text { therapy }(N=60)\end{array}$ \\
\hline \multicolumn{5}{|l|}{ Waist circumference } \\
\hline Baseline prevalence (\%) & $100 a(N=55)$ & $100 a(N=54)$ & $100 \mathrm{a}(\mathrm{N}=55)$ & $100 a(N=60)$ \\
\hline 1-year prevalence (\%) & $94.5 a(N=52)$ & $90.7 a(N=49)$ & $90.9 a(N=50)$ & $90.0 a(N=54)$ \\
\hline$\%$ cases resolved & $5.5 a(\mathrm{~N}=3)$ & $9.3 a(N=5)$ & $9.1 \mathrm{a}(\mathrm{N}=5)$ & $10.0 a(\mathrm{~N}=6)$ \\
\hline$\%$ cases developed & $0.0 a(\mathrm{~N}=0)$ & $0.0 a(N=0)$ & $0.0 a(\mathrm{~N}=0)$ & $0.0 \mathrm{a}(\mathrm{N}=0)$ \\
\hline \multicolumn{5}{|l|}{$H D L$} \\
\hline Baseline prevalence (\%) & $29.1 \mathrm{a}(\mathrm{N}=16)$ & $40.7 a(N=22)$ & 30.9a (N=17) & $35.1 \mathrm{a}(\mathrm{N}=21)$ \\
\hline 1-year prevalence (\%) & 27.3a $(\mathrm{N}=15)$ & $42.6 a(N=23)$ & $30.9 a(N=17)$ & $33.3 a(N=20)$ \\
\hline$\%$ cases resolved & $25.0 a(N=4)$ & $22.3 a(N=5)$ & $23.5 a(N=4)$ & $47.6 a(N=6)$ \\
\hline$\%$ cases developed & 7.7a $(\mathrm{N}=3)$ & $18.8 \mathrm{a}(\mathrm{N}=6)$ & $10.5 a(N=4)$ & $12.8 \mathrm{a}(\mathrm{N}=5)$ \\
\hline \multicolumn{5}{|l|}{ Blood pressure } \\
\hline Baseline prevalence (\%) & $52.7 a(N=29)$ & 37.0a $(\mathrm{N}=20)$ & $52.7 \mathrm{a}(\mathrm{N}=29)$ & 40.0a $(\mathrm{N}=24)$ \\
\hline 1-year prevalence (\%) & 49.1a $(\mathrm{N}=27)$ & 46.3a $(\mathrm{N}=25)$ & $38.2 \mathrm{~b}(\mathrm{~N}=21)$ & 25.0ab $(\mathrm{N}=15)$ \\
\hline$\%$ cases resolved & $24.1 \mathrm{a}(\mathrm{N}=7)$ & $15.0 \mathrm{a}(\mathrm{N}=3)$ & $34.5 a(N=10)$ & $50.0 a(\mathrm{~N}=12)$ \\
\hline$\%$ cases developed & $19.2 \mathrm{a}(\mathrm{N}=5)$ & $23.5 \mathrm{a}(\mathrm{N}=8)$ & $7.7 \mathrm{a}(\mathrm{N}=2)$ & $8.3 a(N=3)$ \\
\hline \multicolumn{5}{|l|}{ Triglycerides } \\
\hline Baseline prevalence (\%) & $25.5 a(N=14)$ & $31.5 a(\mathrm{~N}=17)$ & $25.5 a(N=14)$ & $23.3 a(N=14)$ \\
\hline 1-year prevalence (\%) & 27.3a $(\mathrm{N}=15)$ & 29.6a $(\mathrm{N}=16)$ & $10.9 b(\mathrm{~N}=6)$ & $11.7 b(\mathrm{~N}=7)$ \\
\hline$\%$ cases resolved & 42.9a $(\mathrm{N}=6)$ & $23.5 a(N=4)$ & $57.1 \mathrm{a}(\mathrm{N}=8)$ & $78.6 a(\mathrm{~N}=11)$ \\
\hline$\%$ cases developed & $17.1 \mathrm{a}(\mathrm{N}=7)$ & $8.1 \mathrm{ab}(\mathrm{N}=3)$ & $0.0 \mathrm{~b}(\mathrm{~N}=0)$ & 8.7ab $(\mathrm{N}=4)$ \\
\hline \multicolumn{5}{|l|}{ Glucose } \\
\hline Baseline prevalence (\%) & 10.9a $(\mathrm{N}=6)$ & $18.5 a(\mathrm{~N}=10)$ & 10.9a $(\mathrm{N}=6)$ & $5.0 a(N=3)$ \\
\hline 1-year prevalence (\%) & $9.1 \mathrm{a}(\mathrm{N}=5)$ & $9.3 a(N=5)$ & 3.6a $(\mathrm{N}=2)$ & 3.3a $(\mathrm{N}=2)$ \\
\hline$\%$ cases resolved & $50.0 a(N=3)$ & 70.0a $(\mathrm{N}=7)$ & 66.6a $(\mathrm{N}=4)$ & $100 a(N=3)$ \\
\hline$\%$ cases developed & $4.1 \mathrm{a}(\mathrm{N}=2)$ & 4.6a $(\mathrm{N}=2)$ & $\mathrm{Oa}(\mathrm{N}=0)$ & 3.5a $(\mathrm{N}=2)$ \\
\hline
\end{tabular}

Across rows, values with different subscripts differ significantly based on $\chi^{2}$ tests, $P<0.05$. 
Figure 1: Baseline prevalence (\%) of metabolic syndrome and its components

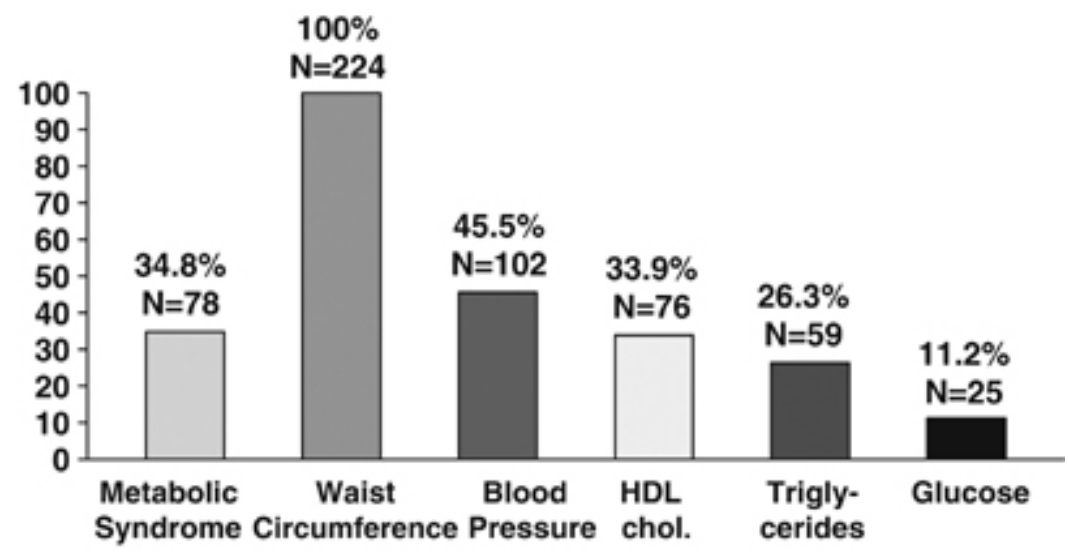




\section{References}

1. Ford ES, Giles WH, Dietz WH. Prevalence of the metabolic syndrome among US adults: Findings from the Third National Health and Nutrition Examination Survey. JAMA 2002; 287: 356-359.

2. Lakka HM, Laaksonen DE, Lakka TA. The metabolic syndrome and total and cardiovascular disease mortality in middle-aged men. JAMA 2002; 288: 2709-2716.

3. Onat A, Ceyhan K, Basar O, Erer B, Toprak S, Sansoy V. Metabolic syndrome: major impact on coronary risk in a population with low cholesterol levels - a prospective and crosssectional evaluation. Atherosclerosis 2002; 165: 285-292.

4. Laaksonen DE, Lakka HM, Niskanen LK, Kaplan GA, Salonen JT, Lakka TA. Metabolic syndrome and development of diabetes mellitus: Application and validation of recently suggested definitions of the metabolic syndrome in a prospective cohort study. Am J Epidemiol 2002; 156: 1070-1077.

5. Resnick HE, Jones K, Ruotolo G. Insulin resistance, the metabolic syndrome, and risk of incident cardiovascular disease in nondiabetic American Indians: The Strong Heart Study. Diab Care 2003; 26: 861-867.

6. Grundy SM, Becker D, Clark LT, Cooper RS, Denke MA, Howar DWJ et al. Executive Summary of The Third Report of The National Cholesterol Education Program (NCEP) Expert Panel on Detection, Evaluation, and Treatment of High Blood Cholesterol In Adults (Adult Treatment Panel III). JAMA 2001; 285: 2486-2497.

7. Lofgren IE, Herron KL, West KL, Zern TL, Brownbill RA, Ilich JZ et al. Weight loss favorably modifies anthropometrics and reverses the metabolic syndrome in premenopausal women. J Am Coll Nutr 2005; 24: 486-493.

8. Poppitt SD, Keogh GF, Prentice AM, Williams DEM, Sonnemans HMW, Valk WJ et al. Long-term effects of ad libitum low-fat, high-carbohydrate diets on body weight and serum lipids in overweight subjects with metabolic syndrome. Am J Clin Nutr 2002; 75: 11-20.

9. Case CC, Jones PH, Nelson K, Smith EO, Ballantyne CM. Impact of weight loss on the metabolic syndrome. Diab Obes Metab 2002; 4: 407-414.

10. Xydakis AM, Case CC, Jones PH, Hoogoveen RC, Liu M, Smith EO et al. Adiponectin, inflammation, and the expression of the metabolic syndrome in obese individuals: The impact of rapid weight loss through caloric restriction. J Clin Endocrin Metab 2004; 89: 2697-2703.

11. Assali AR, Ganor A, Beigel Y, Shafer Z, Hershcovici T, Fainaru M. Insulin resistance in obesity: body weight or energy balance? J Endocrinol 2001; 171: 293-298.

12. Nicklas B, Dennis KE, Berman DM, Sorkin J, Ryan AS, Goldberg AP. Lifestyle intervention of hypocaloric dieting and walking reduces abdominal obesity and improves coronary heart disease risk factors in obese, postmenopausal, African-American and Caucasian women. $\mathrm{J}$ Gerontol A: Biol Sci Med Sci 2003; 58: 181-189.

13. Orchard TJ, Temprosa M, Goldberg RB, Haffner S, Ratner R, Marcovina S et al. The effect of metformin and intensive lifestyle intervention on the metabolic syndrome: The Diabetes Prevention Program Randomized Trial. Ann Int Med 2005; 142: 611-619.

14. Despres JP, Golay A, Sjostrom L, Rimonabant in Obesity-Lipids Study Group. Effects of rimonabant on metabolic risk factors in overweight patients with dyslipidemia. N Engl J Med 2005; 353: 2121-2134.

15. Pi-Sunyer FX, Aronne LJ, Heshmati HM, Devin J, Rosenstock J, RIO-North America Study Group. Effect of rimonabant, a cannabinoid-1 receptor blocker, on weight and cardiometabolic risk factors in overweight or obese patients: RIO-North America: a randomized controlled trial. JAMA 2006; 295: 761-765. 
16. Van Gaal L, Rissanen AM, Scheen AJ, Ziegler O, Rossner S, RIO-Europe Study Group. Effects of the cannabinoid-1 receptor blocker rimonabant on weight reduction and cardiovascular risk factors in overweight patients: 1-year experience from the RIO-Europe study. Lancet 2005; 365: 1389-1397.

17. Wadden TA, Berkowitz RI, Womble LG, Sarwer DB, Phelan S, Cato RK et al. Randomized trial of lifestyle modification and pharmacotherapy for obesity. N Engl J Med 2005; 353: 2111-2120.

18. Brownell KD, Rodin J. The Weight Maintenance Survival Guide. Brownell \& Hager: Dallas, 1990.

19. Brownell KD, Wadden TA. The LEARN Program for Weight Control: Special Medication Edition. American Health Publishing: Dallas, 1999.

20. Haffner SM, Kennedy E, Gonzalez C, Stein MP, Miettinen H. A prospective analysis of the HOMA model. The Mexico City Diabetes Study. Diab Care 1996; 19: 1138-1141.

21. Hall WD, Clark LT, Wenger NK, Wright JT, Kumanyika SK, Watson K et al. The metabolic syndrome in African Americans: a review. Ethn Dis 2003; 13: 414-428.

22. Park YW, Zhu S, Palaniappan L, Heshka S, Carnethon MR, Heymsfield SB. Prevalence and associated risk factor findings in the US population from the Third National Health and Nutrition Examination Survey, 1988-1994. Arch Int Med 2003; 163: 427-436.

23. Kukkonen-Harjula KT, Borg PT, Nenonen AM, Fogelholm MG. Effects of a weight maintenance program with or without exercise on the metabolic syndrome: a randomized trial in obese men. Prev Med 2005; 41: 784-790.

24. Fogelholm M, Kukkonen-Harjula K, Nenonen A, Pasanen M. Effects of walking training on weight maintenance after a very-low-energy diet in premenopausal obese women: a randomized controlled trial. Arch Int Med 2000; 160: 2177-2184.

25. Norris SL, Zhang X, Avenell A, Gregg E, Schmid CH, Kim C et al. Efficacy of pharmacotherapy for weight loss in adults with type 2 diabetes mellitus. Arch Int Med 2004; 164: 1395-1404.

26. Arterburn DE, Crane PK, Veenstra DL. The efficacy and safety of sibutramine for weight loss: a systematic review. Arch Int Med 2004; 164: 994-1003.

27. Kim SH, Lee YM, Jee SH, Nam CM. Effect of sibutramine on weight loss and blood pressure: A meta-analysis of controlled trials. Obes Res 2003; 11: 1116-1123.

28. Zhu S, St-Onge M, Heshka S, Heymsfield SB. Lifestyle behaviors associated with lower risks of having the metabolic syndrome. Metabolism 2004; 53: 1503-1511. 


\section{Acknowledgements}

Funding agencies were not involved in the design or conduct of the study; collection, management, analysis, or interpretation of the data; or preparation, review, or approval of the manuscript. Drs Wadden and Phelan designed the study. Drs Berkowitz, Sarwer, Womble and Cato treated the patients and contributed to the revision of the paper with critical input from the other authors. Ms Rothman provided administrative, technical and logistic support and assembled the data. Dr Phelan analyzed the data and prepared the first draft of the manuscript, which was revised with the critical input from Dr Wadden and the other coauthors. All authors have approved the submission of the manuscript. Dr Phelan, as the principal investigator of this secondary study, had full access to all the data in the investigation and takes responsibility for the integrity of the data, the accuracy of the data analysis and acknowledgement of all author contributions. This research was supported by grants DK56124 and DK065018 from the National Institutes of Diabetes Digestive and Kidney Disease. Abbott Laboratories provided the medication used in the study. Drs Wadden and Berkowitz have served as consultants to Abbott laboratories, which manufacture sibutramine. 